\title{
RUPTURE OF VESICOURETHRAL ANASTOMOSIS FOLLOWING RADICAL RETROPUBIC PROSTATECTOMY
}

\author{
MARCOS DALL'OGLIO, MIGUEL SROUGI, DANIEL PEREIRA, ADRIANO NESRALLAH, \\ CÁSSIO ANDREONI, JOSÉ R. KAUFFMANN, LUCIANO NESRALLAH \\ Department of Urology, Federal University of São Paulo, UNIFESP, Paulista School of \\ Medicine, São Paulo, SP, Brazil
}

\begin{abstract}
Objective: Rupture of vesicourethral anastomosis following radical retropubic prostatectomy is a complication that requires immediate management. We evaluated the morbidity of this rare complication.

Materials and Methods: We analyzed retrospectively 5 cases of disruption of vesicourethral anastomosis during post-operative period in a consecutive series of 1,600 radical retropubic prostatectomies, performed by a single surgeon.

Results: It occurred in a ratio of $1: 320$ prostatectomies $(0,3 \%)$. Management was conservative in all the cases with an average catheter permanence time of 28 days, being its removal preceded by cystography. Two cases were secondary to bleeding, 1 followed the change of vesical catheter and 2 by unknown causes after removing the Foley catheter. Only one patient evolved with urethral stenosis, in the period ranging from 6 to 120 months.

Conclusion: Rupture of vesicourethral anastomosis is not related to the surgeon's experience, and conservative treatment has shown to be effective.
\end{abstract}

Key words: prostatic neoplasms; retropubic prostatectomy; anastomosis, surgical; rupture Int Braz J Urol. 2003; 29: 221-227

\section{INTRODUCTION}

Prostate adenocarcinoma is a worldly public health problem, and about 2 hundred thousand men had a prostate cancer diagnosed in the USA in 2001 (1), with a forecast of forty thousand deaths (2). Routine use of prostate-specific antigen (PSA) has favored early diagnosis of prostate cancer $(3,4)$ and, thus, has improved the results of surgical treatment in controlling the neoplasm $(1,2,5)$. After significant advances in the surgical technique established by Walsh et al. (6), including preservation of neurovascular bundle and a better control of the penile dorsal vein complex, radical prostatectomy has become safe and feasible for most urologists. Two decades after the publishing of Walsh's technique (6), several surgeons have already achieved a large experience, obtaining expressive series of treated patients (7-9), with ma- jor immediate and late complications related to radical prostatectomy being well documented $(5,10-13)$.

Disruption of vesicourethral anastomosis following radical retropubic prostatectomy (RRP) is a rare complication and, undoubtedly, a dramatic situation for the surgeon to decide between surgical intervention and conservative management (7). Management is controversial, since the superiority of a particular treatment method has not been established.

The objective of this study is to demonstrate our experience when facing a rupture of vesicourethral anastomosis following radical prostatectomy.

\section{MATERIALS AND METHODS}

One thousand and six hundred consecutive patients submitted to RRP associated to bilateral iliac lymphadenectomy due to prostate carcinoma, per- 
formed by a single surgeon (MS) at our Institution, in the period from January 1988 to November 2002 were retrospectively assessed. Our study included 5 patients with ages ranging from 55 to 72 years $($ mean $=64.8$ years) and who presented disruption of vesicourethral anastomosis during RRP post-operative. In 2 patients, the disruption occurred due to bleeding in surgical resection bed, one due to inadvertent change of Foley catheter and 2 ruptures of anastomosis occurred in the first and in the tenth day after Foley catheter removal, 13 and 23 days post-operatively respectively.

Immediate management consisted in urethrocystoscopy associated with introducing of a guide-wire and positioning of Foley catheter by fluoroscopy in 4 cases. Only 1 patient was immediately catheterized. Follow-up was performed through weekly cystographic examination, with removal of Foley catheter after absence of extravasation of contrast media confirmed in urethrocystography. Follow- up ranged from 6 to 120 months (mean $=25.2$ months). Patients were assessed through anamnesis, with emphasis on voiding patterns and monthly urethrocystography during the first semester, bi-annual PSA, abdomen tomography and bone scintigraphy yearly.

\section{RESULTS}

Table-1 presents the etiology of the rupture of anastomosis and early clinical manifestations. Table-2 demonstrates the repercussions of long-term permanence of the Foley catheter.

Of the 5 cases of rupture of vesicourethral anastomosis following radical retropubic prostatectomy analyzed, 4 evolved satisfactorily and 1 presented sclerosis of the anastomosis, requiring the introduction of an urethral stent. Next, we present the report on each case in details.

Table 1 - Characteristics of rupture of vesicourethral anastomosis.

\begin{tabular}{lccc}
\hline Patient & Cause of Rupture & Manifestation & POD \\
\hline 1 & Change of Foley catheter & Low urinary output & 5 \\
2 & $?$ & Urinary retention & $13^{*}$ \\
3 & Bleeding & Anemia & 4 \\
4 & $?$ & Urinary retention & $23^{*}$ \\
5 & Bleeding & Anemia & 2 \\
\hline
\end{tabular}

* Following removal of Foley catheter; POD: Post-operative day.

Table 2 - Period with vesical catheter and complications.

\begin{tabular}{lcccc}
\hline Patient & $\begin{array}{c}\text { Days with } \\
\text { Foley Catheter }\end{array}$ & $\begin{array}{c}\text { Sclerosis of } \\
\text { Bladder Neck }\end{array}$ & $\begin{array}{c}\text { Urinary } \\
\text { Continence }\end{array}$ & $\begin{array}{c}\text { Prolonged Urinary } \\
\text { Incontinence }\end{array}$ \\
\hline 1 & 31 & No & Yes & No \\
2 & 22 & No & Yes & No \\
3 & 14 & No & Yes & No \\
4 & 31 & Yes & No & Yes * \\
5 & 42 & No & Yes & Yes \\
\hline
\end{tabular}

* Placement of stent (Urolume); * placement of AMS 800 artificial sphincter 


\section{Case 1: RM, 64 years, stage pT2b, Gleason 2+3}

On the third post-operative day (POD) the Foley catheter was changed by nursing. Subsequently there was inversion of urinary output, being larger through suprapubic Penrose drain and lower through the Foley catheter. On 5th POD, the confirmation of disruption of vesicourethral anastomosis was established during cystoscopy (Storz flexible cystoscope). During this procedure, a vesical catheter was placed with the aid of a guide-wire and cystographic control insufflating Foley's balloon with $60 \mathrm{~mL}$ of a solution containing iodated contrast media. Release from hospital was granted on 8th POD and the patient remained with Foley catheter for 31 days. Urinary continence was established in a definitive way from the third month on, when hygienic diapers were dispensed, however the patient evolved with erectile dysfunction.

\section{Case 2: SM, 65 years, stage pT3a, Gleason 4+3}

Following removal of Foley catheter on 13th POD the patient evolved with acute urinary retention. An urethrocystoscopy was performed, showing a disruption of anastomosis, which remained united only by one point. Management was conducted on an outpatient basis, by introducing a Foley catheter under fluoroscopy with the aid of a guide-wire previously inserted in the bladder. On 35th POD, the vesical catheter was removed after a normal urethrocystography. The patient evolved without intercurrences remaining continent and with sexual potency preserved.

\section{Case 3: FB, 55 years, stage pT3a, Gleason 3+2}

On 4th POD, patient evolved with pallor, tachycardia, sweating and interruption of urinary output through Foley catheter associated to a drop in serum hemoglobin levels. Five units of erythrocyte concentrate were transfused for correction of anemia. A fluoroscopy was performed and a new vesical catheter was introduced with the aid of a guide-wire through uretrocystoscopy, which evidenced the disruption of vesicourethral anastomosis associated with the presence of hematoma between the anastomosis margins, extending hospital permanence to 8 days until clinical stability. The Foley catheter was removed on the 14th POD, after a normal urethrocystography, and during follow-up, the patient did not present any voiding difficulty remaining continent and with sexual potency preserved.

\section{Case 4: JCB, 68 years, stage pT2b, Gleason 3+3}

On 23rd POD, 10 days after removal of Foley catheter, the patient who was maintaining spontaneous diuresis entered in acute urinary retention. Introduction of a vesical catheter was performed without the need of aids from cystoscopy with drainage of $500 \mathrm{~mL}$ of clear urine. Disruption of vesicourethral anastomosis was confirmed by cystography, which demonstrated extravasation of contrast media. Removal of Foley catheter took place on the 54th POD, after performing an urethrocystography, which showed vesical filling and absence of extravasation of contrast media.

Patient evolved with sclerosis of the vesical neck (vesico-urethral anastomosis site), which was corrected by urethral stenting (Urolume ${ }^{\circledR}$ ). After the procedure, the patient manifested urinary incontinence, which was subsequently resolved by placing an AMS 800 artificial sphincter. Sexual function is satisfactory with the aid of intracavernous injections of prostaglandin.

\section{Case 5: J G, 72 years, stage pT2c, Gleason 4+3}

On 2nd POD patient presented an acute myocardial infarction and was subjected to coronary angioplasty with placement of a vascular stent associated to administration of anti-platelet aggregating factor. He evolved with massive pelvic hemorrhage and hemodynamic instability, requiring the transfusion of 6 units of erythrocyte concentrate to correct anemia. Computerized tomography demonstrated disruption of the vesicourethral anastomosis separated by a large hematoma that pushes the bladder cranially (Figure-1). This hematoma was drained through puncture guided by computerized tomography (Figure-2). After 3 weeks with Foley catheter, it was removed; however, patient evolved with acute urinary retention. Foley catheter was reinserted with the aid of urethrocystoscopy with introduction of a guidewire and positioning with fluoroscopic assistance. Control cystography performed after 42 days, demonstrated persistence of extravasation of contrast 


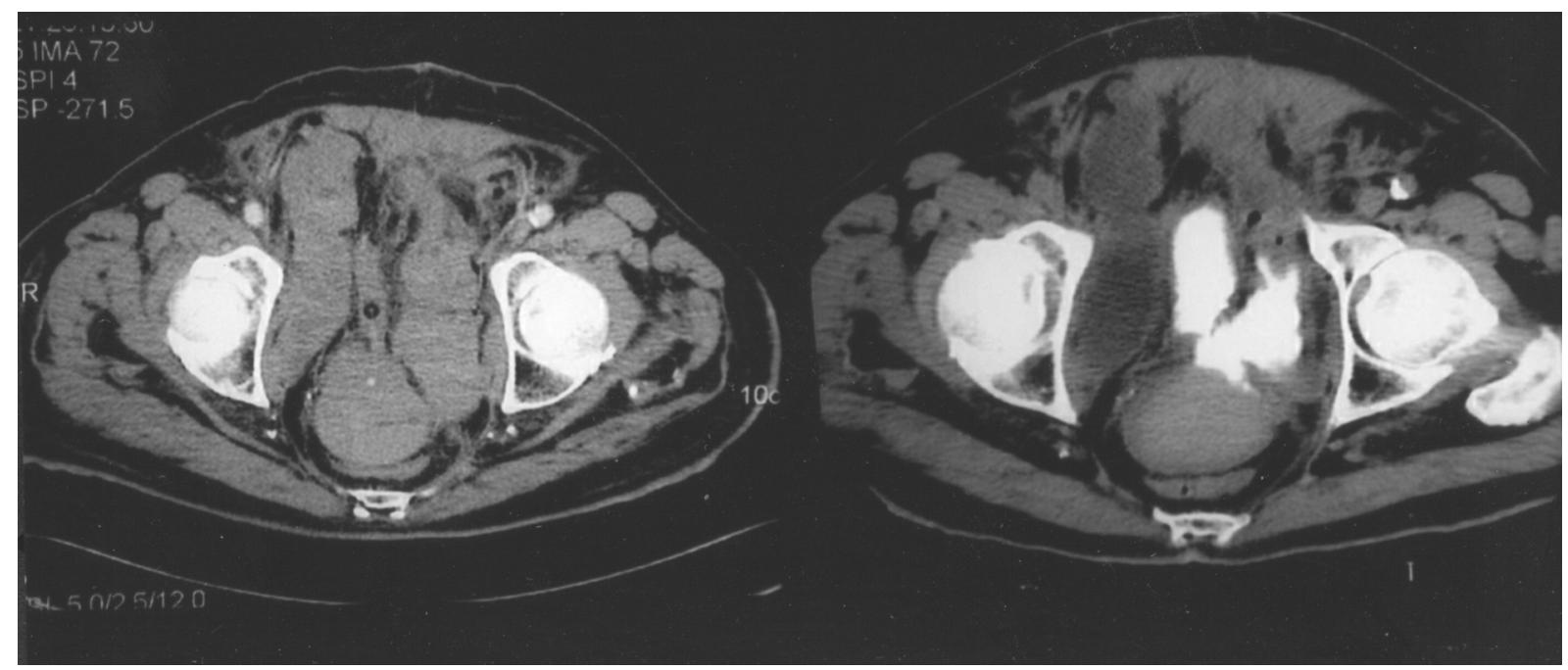

Figure 1 - Perivesical hematoma causing rupture of vesicourethral anastomosis evidencing by extravasation of contras medium.

media, with the aggravation that Foley catheter was positioned outside the bladder (Figure-3). Foley catheter was repositioned with the aid of cystoscopy and dynamic cystography with insufflation of $80 \mathrm{~mL}$ of contrast medium in the catheter balloon. During the passage of the cystoscope there was drainage of hematic secretion around the device. Weekly urethrocystographies were performed, until complete urethrovesical healing (Figure-4).Vesical catheter was

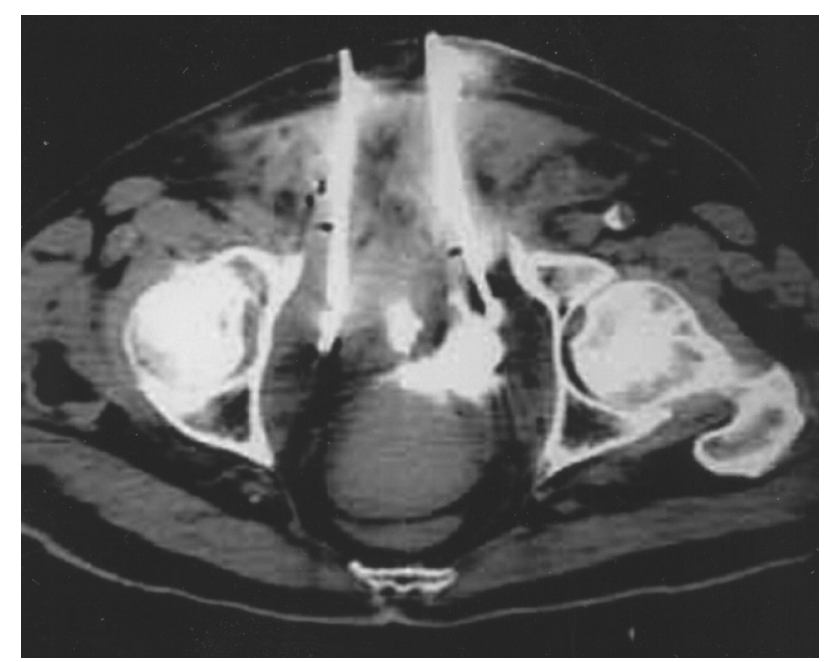

Figure 2 - Percutaneous drainage of hematoma, guided by computerized tomography. removed after 30 days (83rd POD), with patient obtaining spontaneous diuresis. Currently, after a 6 months follow-up, the patient is continent.

\section{DISCUSSION}

This work demonstrated that conservative management for treating post-RRP rupture of vesicourethral anastomosis through permanence of

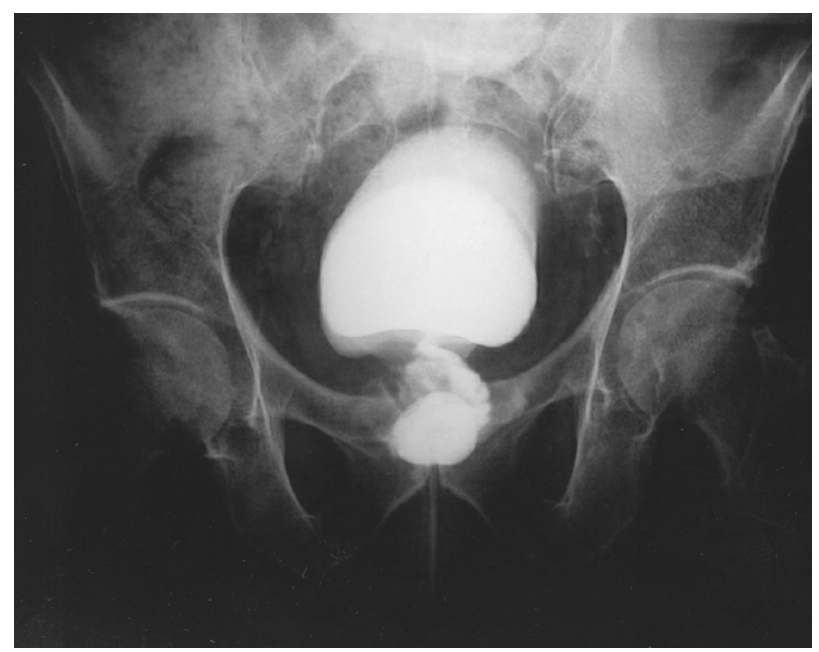

Figure 3 - Complete dehiscence of bladder neck with escape of Foley catheter associated to cranial displacement of the bladder. 


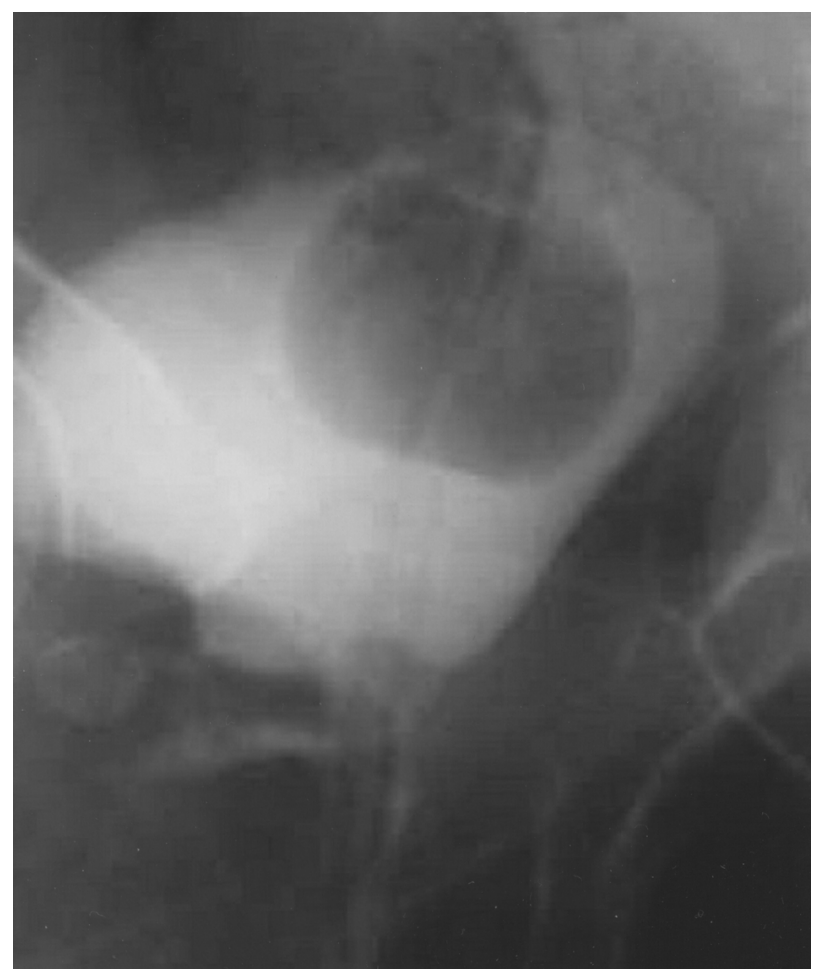

Figure 4 - Cystographic control showing minimum extravasation of contrast medium and descending of bladder to its anatomical position.

Foley catheter was effective. The incidence of disruption of vesicourethral anastomosis is $0.2 \%$ to $0.5 \%$ (7-9) and the best management is still a subject for discussion.

The most common transoperative complication of radical prostatectomy is bleeding (8), which decreases with surgeon's expertise (10), however, with a blood transfusion rate of $9 \%$ to $29 \%(5,8)$, what can reflect in prognosis (11). Acute myocardial infarction is the most common unrelated post-operative complication (10) oscillating between $0.1-0.5 \%$ $(8,9,12)$, on the other hand, the need of using an anticoagulant increases intraoperative bleeding and postoperative lymphatic drainage (10). We had a patient who presented an acute myocardial infarction on 2 nd POD in whom the use of anti-platelet aggregating factor had precipitated the hemorrhage.

On the other hand, the incidence of significant bleeding in the dissection bed during post-operative period ranges from $0.3 \%$ to $3.2 \%(7,9,12,14)$ and the need of blood transfusion is very rare (10). Formation of small hematomas suggests an expectant management (10), however bulky hematomas can compress and displace the bladder causing disruption of vesicourethral anastomosis, if they are not drained (7). In our series, 2 patients had bleeding with rupture of anastomosis whose conservative treatment was effective. In one case there was the need of draining the perivesical hematoma through punction guided by computerized tomography in order to avoid infection and to control severe perineal pain.

Hedican \& Walsh (7) studied 7 patients with rupture of vesicourethral anastomosis secondary to bleeding in surgical bed, dividing the patients in 2 groups. In the first group, comprised by 3 patients, a conservative treatment was instituted, with indwelling vesical catheterization, whose outcome revealed sclerosis of vesical neck in all 3 patients, with 2 of them evolving with prolonged urinary incontinence. The second group, submitted to surgical exploration for hematoma drainage with revision of anastomosis had a better outcome, presenting sclerosis of vesical neck in 1 patient and prolonged urinary incontinence in another one. When indicating a new surgery in cases of post-radical prostatectomy pelvic hematomas, Lepor et al. (9), advised the repair of vesicourethral anastomosis.

Conservative treatment can be associated to sclerosis of vesical neck and also to prolonged urinary incontinence $(7,15)$, on the other hand, early intervention with suturing of urethral margins increases the risk of complications such as urinary incontinence, erectile dysfunction and bleeding (16). In our cases, out of 5 treated patients, we had one case of sclerosis of vesical neck refractory to endoscopic treatment, whose definitive treatment consisted in the placement of a stent (Urolume), however the patient evolved with urinary incontinence requiring the implantation of an artificial sphincter (AMS-800) in order to solve definitely the problem.

When facing disruption of vesicourethral anastomosis, in order to reposition Foley catheter, cystoscopy with introduction of a guide-wire is fundamental $(10,15)$, and while introducing the catheter, its position must be confirmed by fluoroscopy with contrast injection. Differently from Fisher \& Koch 
(15), we did not fix the catheter on the vesical dome; we simply used the artifice of insufflating the Foley catheter's balloon with a volume around $60 \mathrm{~mL}$. Despite this precaution, in one case occurred a displacement of the Foley catheter outwards the bladder, due to complete dehiscence of vesical cervix with cranial displacement of bladder. In radical retropubic prostatectomy, while confectioning the new vesical neck, we usually use a 2-zero chromium catgut suture, making separate stitches in total plane and vesicourethral anastomosis is done with 8 separate stitches with poliglactin 3-zero incorporating the striated sphincter together with the urethra. Normally, we remove the Foley catheter on 13th POD, however there are series indicating the catheter's removal in an earlier period without impairment in healing (14). We had 2 cases of urinary retention following removal of the Foley catheter, on the first and on the 10th days following catheter's removal, without evidencing the reason for such rupture. In only one case premature change of catheter promoted the disruption of the anastomosis.

We believe that rupture of anastomosis is not related to the surgeon's experience, considering the occurrence of such complication in teams with expressive casuistry (7-9), neither is it changed by the number of stitches used for vesicourethral anastomosis $(5,8,9,13,15,17,18)$. Antibiotic therapy was used in all patients, and no cases of sepsis were recorded. Upon confirmation of stability in the clinical picture and adequate positioning of the Foley catheter, patient is released from hospital with oral antibiotics and is re-evaluated every week on an outpatient basis through cystography, thus avoiding an excessive increase on treatment costs.

Analogously to trauma of posterior urethra, where there is disruption of prostate-membranous urethra with cranial displacement of the bladder, introducing of a Foley catheter through the urethral route allows the alignment of margins with a lower incidence of stenosis in the region, and subsequent descending of bladder to its anatomical position (15), because of this, we do not advise performing a cystostomy. Prolonged drainage constitutes an adequate management and avoids potential failure in a new surgery.

\section{REFERENCES}

1. Eton DT, Lepore SJ, Helgeson VS: Early quality of life in patients with localized prostate carcinoma. Cancer 2001; 92:1451-9.

2. Berry MJ, Albertsen PC, Bagshaw MA, Blute ML, Cox R, Middleton RG et al.: Outcomes of men with clinically nonmetastatic prostate carcinoma managed with radical prostatectomy, external beam radiotherapy, or expectant management. Cancer 2001; 91:2302-14.

3. Jacobsen SJ, Kausis SV, Bergstralh EJ, Oesterling JE, Orth, D, Klee GG et al.: Incidence of prostate cancer diagnosis in the eras before and after serum prostatespecific antigen testing. JAMA 1995; 274:1445-9.

4. Epstein JI, Walsh PC, Carter HB: Dedifferentiation of prostate cancer grade with time in men followed expectantly for stage T1c disease. J Urol. 2001; 166:1688-91.

5. Dillioglugil O, Leibman D, Leibman NS, Kattan MW, Rosas AL, Scardino PT: Risk factors for complication and morbidity after radical retropubic prostatectomy. J Urol. 1997; 157:1760-7.

6. Walsh PC, Partin AW, Epstein JI: Cancer control and quality of life following anatomical radical retropubic prostatectomy. Results at 10 years. J Urol. 1984; 152:1831-6.

7. Hedican SP, Walsh PC: Postoperative bleeding following radical retropubic prostatectomy. J Urol. 1994; 152:1181-3.

8. Catalona WJ, Carvalhal GF, Mager DE, Smith DS: Potency, continence and complication rates in 1,870 consecutive radical retropubic prostatectomies. J Urol. 1999; 162:433-8.

9. Lepor H, Nieder AM, Ferrandino MN: Intraoperative and postoperative complications of radical retropubic prostatectomy in a consecutive series of 1000 cases. J Urol. 2001; 166:1729-33.

10. Shekarriz B, Upadhyay J, Wood DP: Intraoperative, perioperative, and long-term complications of radical prostatectomy. Urol Clin North Am. 2001; 28:639-53.

11. Oefelein MG, Conlangelo LA, Rademaker AW, McVary KT: Intraoperative blood loss and prognosis in prostate cancer patients undergoing radical retropubic prostatectomy. J Urol. 1995; 154:442-7.

12. Lu-Yao GL, Albertsen P, Warren J, Yao SL: Effect of age and surgical approach on complications and shortterm mortality after radical prostatectomy. A population-based study. Urology 1999; 54:301-7.

13. Heinzer H, Graefen M, Noldus J, Hammerer P, Huland $\mathrm{H}$ : Early complication of anatomical radical prostate- 
ctomy: Lessons from a single-center experience. Urol Int. 1997; 59:30-3.

14. Guillonneau B, Rozet F, Cathelineau X, Lay F, Barret E, Doublet JD et al.: Perioperative complications of laparoscopic radical prostatectomy: The Montsouris 3-years experience. J Urol. 2002; 167:51-6.

15. Fisher RE, Koch MO: Recognition and management of delayed disruption vesicourethral anastomosis in radical prostatectomy. J Urol. 1992; 147:1579-81.

16. Kotkin L, Koch MO: Impotence and incontinence af- ter immediate realignment of posterior urethral trauma: result of injury or management? J Urol. 1996; 155:1600-3.

17. Igel TC, Barrett DM, Rife CC: Comparison of techniques for vesicourethral anastomosis: simple direct modified Vest traction sutures. Urology 1988; 31:474-7.

18. Petroski RA, Thrasher JB, Hansberry KL: New use of Foley catheter for precise vesicourethral anastomosis during radical retropubic prostatectomy. J Urol. 1996; 155:1376-7.

Received: February 21, 2003

Accepted: April 4, 2003

\author{
Correspondence address: \\ Dr. Marcos Dall'Oglio \\ Rua Manoel da Nóbrega, 853 casa 22 \\ São Paulo, SP, 04001-084, Brazil \\ Fax: + $55113885-0658$ \\ E-mail: marcosdalloglio@uol.com.br
}

\section{EDITORIAL COMMENT}

Fortunately it is an uncommon situation, but a rather concerning one. The authors were very fortunate when choosing conservative management, with excellent results in the 5 cases presented. We entirely agree that this complication is not related to the learning curve.

However, being controversial, immediate surgical approach must be restricted to surgeons with a larger casuistry, thus avoiding major complications, such as sphincter compromise, leading to urinary incontinence, as well as lesions of neurovascular bundle.

In our casuistry, using continuous suture in 471 cases of radical retropubic prostatectomy, there were no cases of rupture of vesicourethral anastomosis. It is interesting to emphasize that in 6 patients with short urethras that were too much embedded into the urogenital diaphragm, in addition to such adverse pelvic anatomy, it was impossible to perform the vesicourethral continuous suture $(1.2 \%$; 6 in 477 consecutive RRP). Of these patients, 2 presented rupture of anastomosis during immediate post-operative, as a consequence of replacement of Foley catheter by nursing. These 2 patients were immediately reoperated, and it was verified that the Foley catheters balloons had been insufflated in the anastomosis area, tearing it completely. We performed a new vesicourethral anastomosis with 6 separate stitches. The Foley catheter was maintained for 4 weeks and the patients were continent after 6 months.

We believe that continuous suture of vesicourethral anastomosis enables the safe removal of the Foley catheter on 3rd or 4th post-operative day, and additionally can prevent the rupture of vesicourethral anastomosis.

Dr. Aloysio Floriano de Toledo Section of Urology, General Hospital Catholic University of Rio Grande do Sul Porto Alegre, Rio Grande do Sul, Brazil 